\title{
O LOBBY DOS TRABALHADORES NO PROCESSO CONSTITUINTE DE 1987-88: UM ESTUDO SOBRE A ATUAÇÃO DO DIAP
}

The worker's lobby in the constituent process of 1987-88: a study about DIAP's performance

\section{LUCAS NASCIMENTO FERRAZ COSTA}

http://dx.doi.org/10.1590/S2178-14942016000300011

\footnotetext{
Lucas Nascimento Ferraz Costa é mestre e doutorando em Ciência Política na Universidade Federal de São Carlos (lucasnfcosta@gmail.com).

Artigo recebido em 13 de janeiro e aprovado para publicação em 26 de setembro de 2016.
} 


\section{RESUMO}

0 objetivo deste artigo é mostrar a influência da atuação de grupos de interesse na constitucionalização de direitos do trabalho durante o processo constituinte de 1987-88. Sustentamos que os interesses da classe trabalhadora foram articulados pelo Departamento Intersindical de Assessoria Parlamentar (DIAP), através de um projeto consensual para a área do trabalho, o qual foi apoiado pelas principais entidades sindicais, pelos partidos políticos de esquerda e pela parcela progressista do PMDB. Por meio da reconstrução da trajetória do DIAP mostramos como o pacto foi formado e que estratégias de lobby foram utilizadas.

Palavras-Chave: Constituinte de 1987-88; Constituição de 1988; DIAP; direitos do trabalho; grupos de interesse; lobby.

\section{AbSTRACT}

The aim of this paper is to show the influence of interest groups in the constitutionalization of labor rights during the constituent process of 1987-88. We sustain that the working class interests were articulated by the Inter-Parliamentary Advisory Department (DIAP), through a consensual project to the labor area, which was supported by the main unions, by left political parties and by the progressive wing of PMDB. Through the reconstruction of DIAP's trajectory we show how the pact was built and which lobby strategies were used.

KeYwORDs: Constituent Assembly of 1987-88; Constitution of 1988; DIAP; labor rights; interest groups; lobby.

\section{RÉSUMÉ}

Le but de cet article est de montrer l'influence des groupes d'intérêt dans la constitutionnalisation des droits du travail pendant le processus constituant de 1987-1988. Nous soutenons que les intérêts de la classe ouvrière ont été articulés par le Conseil Parlementaire Intersyndical (DIAP), au moyen d'un projet consensuel pour le champ du travail qui a été défendu par les principaux syndicats, par les partis politiques de gauche et para I'aile progressiste du PMDB. En reconstituant la trajectoire du DIAP nous montrons comment le pacte a été construit et les stratégies de pression ont été utilisées.

Mots-CLÉS: Assemblée Constituante de 1987-1988; Constitution de 1988; DIAP; droits des travailleurs; groupes d'intérêt; lobby. 


\section{INTRODUÇÃO}

Constituição brasileira de 1988 é produto da transição de uma ditadura para uma
democracia, processo esse que foi marcado pelo desejo de superação da profunda desigualdade social do país através da constitucionalização de direitos sociais e do trabalho. A presença de direitos sociais, com a intensidade e o nível de detalhes da Constituição vigente, é um fenômeno relativamente recente na história constitucional internacional, além de representar um marco dentro do constitucionalismo brasileiro (Noronha, Costa, Troiano, 2014; Costa, 2015).

As reformas constitucionais mais recentes, sobretudo na América do Sul, ${ }^{1}$ sugerem que a constitucionalização de direitos sociais e do trabalho, tradicionalmente classificados como policies e matéria de legislação ordinária, passou a ser objeto de interesse de constituintes e irremediável reivindicação popular em períodos de reforma constitucional.

Sustentamos que a ampliação de direitos sociais e do trabalho como matéria constitucional foi influenciada pela intensificação da participação pública nos processos constituintes, em especial pela atuação de grupos de interesse, hipótese sugerida por diferentes autores (Ginsburg, Elkins, Blount, 2009: 215; Elkins, Ginsburg, Melton, 2009; Samuels, Wyeth, 2006; Blount, 2011).

Neste artigo apresentamos um estudo de caso sobre a atuação do Departamento Intersindical de Assessoria Parlamentar (DIAP) durante o processo constituinte de 1987-88, quando este articulou um projeto consensual para a classe trabalhadora, o qual foi determinante para a constitucionalização de interesses defendidos por entidades sindicais de trabalhadores. Trata-se, portanto, de uma análise de como a inserção de direitos dos trabalhadores na Constituiç̧ão de 1988 foi influenciada pela atuação de grupos de interesse articulados pelo DIAP.

Tradicionalmente, a literatura voltada para o estudo do processo constituinte de 198788 enfatizou sua institucionalidade (as regras do jogo na Assembleia Nacional Constituinte), assim como o papel dos partidos políticos (Pilatti, 2008; Coelho, 1999). A relação entre partidos políticos de esquerda (PCB, PCdoB, PDT, PT e os progressistas do PMDB), entidades sindicais como a Central Única dos Trabalhadores (CUT) e a Central Geral dos Trabalhadores (CGT), e demais grupos de interesse foi pouco analisada. Neste artigo mostramos como a 
atuação do DIAP moldou as preferências dos partidos identificados com os interesses dos trabalhadores, assim como o papel da organização na criação e utilização de mecanismos profissionais de lobby. ${ }^{2}$

Sustentamos que a articulação dos interesses consensuais pelo DIAP foi central na superação de um cenário cujas perspectivas eram favoráveis aos empresários, posto que: (1) 0 poder econômico e a organização da classe empresarial eram muito maiores que os dos trabalhadores no início dos anos 1980 (Costa e Troiano, 2011; Troiano, 2012); (2) a Constituinte foi formada majoritariamente por partidos e parlamentares identificados com os interesses dos empresários (Pilatti, 2008).

Ao enfatizarmos o papel dos grupos de interesse, contudo, não deixamos de reconhecer a importância da dinâmica institucional da ANC - suas regras e sua organização interna, isto é, a explicação endógena ao processo. Sustentamos que o lobby bem-sucedido dos grupos externos à ANC foi justamente aquele que soube reconhecer as oportunidades oferecidas pelas regras do jogo da Constituinte. Portanto, nossa análise está situada na interseção entre uma abordagem da institucionalidade da ANC e seus atores internos (partidos políticos e constituintes) e a influência do lobby dos grupos externos.

Criamos um modelo que sintetiza a estrutura organizacional do DIAP, assim como suas estratégias de atuação, baseado em duas dinâmicas organizacionais: capacidade agregadora e atuação lobista. Além das tradicionais estratégias de lobby utilizadas durante a Constituinte, o DIAP se destacou pela sua capacidade de negociação e seus mecanismos de legitimação perante as lideranças sindicais, sobretudo no período pré-constituinte. As estratégias e a organização institucional do DIAP o caracterizam como um grupo de interesse que incorpora clássicas bandeiras ideológicas da classe trabalhadora. Não se trata, portanto, de uma organização lobista típica, na medida em que não foi construída para atender a interesses específicos de um grupo ou de uma parcela de classes. Sua institucionalização se identifica com um projeto militante da classe trabalhadora, a despeito das divisões e disputas das entidades sindicais da época.

De modo a evidenciar a capacidade de influência do DIAP, traçamos um levantamento histórico da organização, analisando suas estratégias de atuação. Dividimos a história do DIAP em dois momentos do período de transição brasileira. 0 primeiro é anterior à Constituinte: a partir do final de 1983, quando o DIAP foi fundado, até o começo de 1987, quando a ANC foi instalada. Nesse primeiro momento a análise se concentra na capacidade agregadora da organização e na construção de um projeto para a Constituinte, fruto de negociações com as principais organizações sindicais da época. O segundo momento é a análise da atuação do DIAP durante o período em que a ANC esteve em funcionamento (fevereiro de 1987 até setembro de 1988), quando sua atividade lobista foi amplamente repercutida pela imprensa e 
reconhecida até pelos seus adversários políticos. A reconstrução da trajetória da organização levou em consideração variadas fontes primárias, entre as quais destacamos as atas e diários da ANC, documentos elaborados pelo próprio DIAP e por entidades sindicais com as quais este negociou, notícias e artigos de jornais da época, além de entrevistas realizadas com membros do DIAP, lideranças sindicais, deputados e senadores que participaram da Constituinte.

\section{CRIAÇÃo E PREPARAÇÃO PARA A CONSTITUINTE}

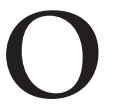

Departamento Intersindical de Assessoria Parlamentar (DIAP) é uma organização fundada em 19 de dezembro de 1983 cuja função inicial, segundo membros da própria entidade, foi organizar as reivindicações consensuais dos trabalhadores, transformando-as em normas legais através da atuação lobista no Congresso Nacional. Isto é, pressionando e convencendo, a partir de diferentes mecanismos, a aprovação de leis de interesse dos trabaIhadores. O DIAP atuou em duas frentes, estruturadas em duas dinâmicas organizacionais: capacidade agregadora e atuação lobista.

Estas duas dinâmicas organizacionais fazem parte de um modelo de análise que elaboramos para a compreensão da atuação do DIAP no período situado entre a data de sua criação e o final da Constituinte. Sua capacidade agregadora é sintetizada pela elaboração de um projeto unificado dos trabalhadores, o qual superou a divisão política entre as entidades sindicais. 0 lobby da organização se baseou em três estratégias principais: elaboração de estudos e projetos de lei; monitoramento de projetos e estudos; emissão de pareceres sobre projetos e estudos apresentados. Inclui-se nos pareceres a estratégia de atribuir notas aos parlamentares de acordo com sua atuação nas questões de interesse dos trabalhadores.

O DIAP foi idealizado pelo advogado trabalhista Ulisses Riedel de Resende, atual diretor-técnico da entidade. A ideia de criar o DIAP surgiu em 1968, quando Riedel foi convidado pelo governo norte-americano, junto com outros cinco advogados brasileiros, a conhecer a organização sindical do país. Em Washington, os advogados visitaram a American Federation of Labor and Congress of Industrial Organizations (AFL-CIO), ${ }^{3}$ onde dois Departamentos chamaram a atenção de Riedel: o encarregado de obter recursos para o financiamento de campanhas, chamado coup, e o Departamento Legislativo, que elaborava projetos de leis, enviava-os ao Congresso e acompanhava, através de lobistas, seu andamento.

Ulisses Riedel revelou em entrevista (Resende, 2011) que, além da elaboração de projetos de lei e seu acompanhamento no Congresso, ficou impressionado com a as notas que o Departamento Legislativo da AFL-CIO atribuía, ao final de cada ano, aos parlamentares, segundo seu desempenho em favor dos trabalhadores. Segundo ele, "essa é uma ideia genial". 
Ela seria colocada em prática pelo DIAP, tornando-se um dos mecanismos de atuação mais famosos da organização.

O exemplo da AFL-CIO inspirou Riedel a criar uma organização semelhante no Brasil já nos anos 1960, mas as restrições ao Congresso, impostas pelo regime militar, inviabilizaram o projeto. 0 desenho institucional de uma organização à imagem da AFL-CIO pressupõe 0 funcionamento pleno do poder legislativo, uma vez que sua principal arena de atuação é o Congresso. Apenas com o processo de abertura democrática em 1974 e do ciclo de greves em 1978 a ideia de emular a experiência americana pôde finalmente ser posta em prática, através do projeto de criação do DIAP.

No final dos anos 1970 Riedel já havia construído uma sólida relação com as principais lideranças sindicais do país, em razão de anos de atuação como advogado trabalhista. Esse prestígio foi fundamental para angariar apoio à criação do DIAP. A primeira liderança sindical que demonstrou apoio ao projeto de Riedel foi o Comandante Aloísio Ribeiro, um dos diretores da Confederação Nacional dos Trabalhadores em Transportes Marítimos, Aéreos e Fluviais (CONTTMAF).

Em agosto de 1981, no I Congresso Nacional de Estivadores, Portuários, Marítimos, Fluviais, Aeroviários, Aeronautas e Pescadores, foi colocado em votação e aprovado o primeiro esboço do que seria o DIAP: "um órgão suprapartidário, desvinculado de qualquer corrente ideológica, partidária ou religiosa, mas comprometido com a defesa dos trabalhadores e comprometido em bem informá-los e também aos parlamentares" (Oliveira, 2005: 222).

Segundo Riedel (Resende, 2011), o apoio da imprensa, através de Armando Rollemberg, nome influente na mídia e que na época era presidente da Confederação Nacional dos Jornalistas, foi importante para buscar maior adesão do movimento sindical. Seguiu-se ao apoio de Rollemberg a adesão dos radialistas e dos ferroviários.

Em 1983, em reunião convocada pelo CONTTMAF, contando com 17 entidades, no auditório da Confederação Nacional dos Trabalhadores na Agricultura (CONTAG), foi articulada a intenção de se criar o DIAP. Nessa reunião foi proposto por Rollemberg que os sindicatos presentes se transformassem na comissão organizadora do DIAP e que fosse feita uma nova convocação com o propósito de buscar a participação de um número maior de entidades. A proposta foi aceita e uma nova reunião foi marcada.

A fundação do DIAP foi adiada por conta de um decreto do então presidente João Figueiredo, de 19 de outubro de 1983, que estabelecia medidas de emergência em Brasília, proibindo reuniões políticas no período de 19 de outubro a 17 de dezembro. ${ }^{4}$ Finalmente em 19 de dezembro de 1983, na sede do CONTAG, em Brasília, foi fundado o DIAP, em uma reunião que contou com 51 entidades. Juntamente com Ulisses Riedel, cinco entidades 
integraram a Comissão Organizadora do Departamento: CONTTMAF; Confederação Nacional das Profissões Liberais (CNPL); Federação Nacional dos Trabalhadores nas Indústrias Urbanas; Federação Nacional dos Estivadores; Federação Nacional dos Trabalhadores em Empresas de Telecomunicações e Operadores de Mesa Telefônica.

A primeira assembleia do DIAP contou com a presença de 51 entidades sindicais de todo o país, as quais aprovaram os estatutos, elegeram e deram posse à primeira diretoria e definiram a contribuição das entidades associadas. Inicialmente, Carlos Falkenberg, então presidente da CNPL, foi empossado como presidente do DIAP. A vice-presidência foi disputada por Maurício Ellena Rangel, presidente da Federação dos Urbanitários, e Antônio Rogério Magri, presidente do Sindicato dos Eletricitários de São Paulo (Stieesp), tendo sido o primeiro o escolhido por ser representante de uma Federação Nacional, enquanto Magri representava um sindicato.

Poucos dias depois Falkenberg deixou a presidência do DIAP, pois só assim poderia permanecer presidente de sua confederação (a CNPL). De acordo com Riedel, estrategicamente era fundamental manter a confederação como aliada, mesmo que isso custasse a condição de presidente do DIAP a Falkenberg. Com isso, a presidência do DIAP foi assumida por Ellena Rangel, então vice. Magri assumiu a vice-presidência.

O principal objetivo do DIAP entre 1983 e 1987 foi organizar e planejar sua atuação na Constituinte. As três ações mais importantes da organização no período foram o lançamento do Jornal do DIAP, em 1985, a publicação do livro Quem é quem, em 1986 e, sobretudo, a criação de cinco projetos de ação com propostas para serem defendidas durante a Constituinte.

O lançamento do Jornal do DIAP em 1985 foi importante, pois o órgão se estabeleceu como o primeiro canal de comunicação entre a organização e as entidades sindicais. Em 1986 o livro Quem é quem foi a primeira publicação que, a exemplo da AFL-CIO, atribuiu notas aos parlamentares de acordo com seu desempenho no tocante a temas considerados pelo DIAP de interesse dos trabalhadores. Foi avaliada a atuação dos deputados da legislatura 1983-1987, levando em consideração as votações dos decretos-leis de arrocho salarial, da estabilidade no emprego (Projeto Um do DIAP, conforme será mostrado a seguir), das Diretas-Já para presidente da República (Emenda Dante de Oliveira), do Colégio Eleitoral (Maluf versus Tancredo), além de declarações dos parlamentares em relação a diversas outras matérias. Ao final do processo constituinte o DIAP publicaria o Quem foi quem na Constituinte, que avaliava o posicionamento dos constituintes durante a ANC.

Foi, contudo, a partir da elaboração dos projetos de ação que o DIAP exerceu seu papel mais importante no período pré-constituinte. A organização elaborou oito projetos, sendo que os seis primeiros antecederam a Constituinte e propunham temas que seriam defendidos pelo DIAP durante os trabalhos na ANC: 
- Projeto Um: proibição de demissão imotivada, defendido antes mesmo da Constituinte através de projeto de lei ordinária que foi aprovado no Congresso. No entanto, com o início da Constituinte não chegou a ser apreciado pelo Senado. Foi retomado na ANC por meio de uma emenda popular, mas não foi aprovado.

- Projeto Dois: poder normativo da Justiça do Trabalho, aprovado na Constituinte, foi inserido no Art. 115, 2ㅜㅡ. da Constituição Federal.

- Projeto Três: organização sindical, não foi bem-sucedido devido às divergências internas entre as várias correntes sindicais. ${ }^{5}$

- Projeto Quatro: ampla garantia ao direito de greve, foi aprovado na Constituição (Art. 9o).

- Projeto Cinco: conjunto de propostas do DIAP para a Constituinte, como a participação dos trabalhadores nos lucros, a cogestão, a reforma agrária, entre outros. Foi em parte conquistado no texto constitucional de 1988.

- Projeto Seis: proposta de salário mínimo. Foi bem-sucedido na Constituinte, pois garantiu a impossibilidade de o governo fixar seu valor por decreto, além de ter ampliado os itens que devem ser cobertos pelo mesmo. ${ }^{6}$

- Projeto Sete: regulamentação de itens constitucionais, como a proibição de demissão imotivada, participação nos lucros, cogestão, entre outros.

- Projeto Oito: revisão constitucional de 1993. Contou com três etapas: pesquisa com formadores de opinião; pesquisa com demais parlamentares; publicação do livro $A$ cabeça do Congresso Nacional - Quem é quem na Revisão Constitucional.?

O Projeto Um concretizou-se através de um anteprojeto de lei criado pelo DIAP em junho de 1984, que proibia a demissão imotivada. Foi acompanhado de uma campanha publicitária nacional organizada pelo próprio DIAP, que contou com cartazes, outdoors, boletins e outros meios de divulgação. 0 Projeto Um foi colocado em pauta no Congresso Nacional, e para isso o DIAP precisou, além da assinatura dos partidos políticos, da de Pimenta da Veiga (PMDB/MG), que era líder do governo Figueiredo. Enquanto todos os partidos assinaram, segundo Riedel foi necessário um trabalho de bastidores para conseguir a assinatura de Pimenta da Veiga. Esta foi uma das primeiras demonstrações de atuação lobista da organização, que contou com a mobilização da mídia e a pressão nos bastidores, como revela o próprio Riedel:

Todos os partidos assinaram pedindo para colocar em pauta e faltava o Pimenta. Aí nós, o movimento sindical, o grupo que estava conosco, disse: "ah, ele vai fazer uma palestra lá em Belo Horizonte, agora dia tal, pras lideranças sindicais. Vamos pressionar ele pra assinar isso." E aí eu digo: "então vocês também levem a imprensa, levem tudo para a coisa ficar bem quente". (...) Até que chegou lá na hora e eu disse "bem agora é um momento histórico, vocês vão ver 
Pimenta da Veiga assinando o pedido. 0 pedido está aqui, assinado por todos os partidos, só falta ele". Ele assinou pedindo a pauta e o processo foi incluído em pauta de votação na Câmara dos Deputados (Resende, 2011).

O DIAP realizava reuniões com um núcleo jurídico formado pelos advogados de todos os sindicatos filiados a ele a fim de discutir as propostas que seriam levadas à Constituinte. A partir dessa aprovação do núcleo jurídico, eram realizados congressos no DIAP para que as lideranças sindicais ratificassem as decisões, o que, conforme afirmou Riedel em entrevista, era feito sem nenhuma resistência:

[...] fizemos congressos no DIAP para que os dirigentes sindicais ratificassem e os dirigentes sindicais nunca discutiram o que o jurídico fez. Quando muito, batiam palmas para isso ou praquilo. Mesmo porque era um trabalho feito cientificamente (Resende, 2011).

Foram realizados cinco congressos nacionais do DIAP, que resultaram em uma ampla adesão do movimento sindical, da qual é símbolo o documento assinado por dez confederações e três centrais sindicais além da Associação Nacional do Ensino Superior (ANDES), no qual todos se comprometiam a apoiar o trabalho do DIAP na defesa dos interesses consensuais dos trabalhadores na Constituinte. Esse documento formalizou o projeto elaborado pela organização, sendo um importante registro formal da consolidação de um bloco unificado de interesses dos trabalhadores.

Consideramos que dois fatores são fundamentais para compreender a influência e a capacidade de articulação do DIAP no meio sindical, que lhe permitiram assumir esse papel centralizador:

1) Desenho institucional atípico na época: inexistiam outras organizações com características semelhantes ao DIAP. Suas características organizacionais, marcadas por um alto grau de profissionalização e elevada capacidade técnica, além de sua estratégia de atuar exclusivamente na defesa de matérias consensuais da sua área de interesse. Assim, a organização não tratava de temas sobre os quais não havia consenso, como por exemplo a organização sindical.

2) 0 prestígio de Ulisses Riedel, criador e diretor-técnico da organização, que era advogado de centenas de entidades sindicais, tendo bom relacionamento com grande parte das lideranças trabalhistas do período. A capacidade agregadora do DIAP era fruto dessa trajetória política de Riedel como advogado trabalhista. Era o DIAP de Riedel, figura bem avaliada pela grande maioria das lideranças sindicais. A formação do consenso foi facilitada, ou somente possível, graças à liderança e capacidade de negociação e articulação de Riedel. 
Antônio Augusto de Queiroz, apontado pela imprensa ${ }^{8}$ como o operador do lobby do DIAP, concorda com esta análise e acrescenta a importância do sucesso obtido pelo Projeto Um do DIAP:

Quando se chegou a um acordo em torno de uma matéria [Projeto Um] que todo mundo entendia como válida e a gente atuou bem nisso, divulgou, fez campanha contra a demissão imotivada, "trabalhador sendo chutado", placas no Brasil inteiro, foi quando se consolidou esse corpo de apoio [...] como a gente não se meteu em matérias que conflitavam, foi razoavelmente fácil (Queiroz, 1997).

0 projeto defendido pelo DIAP na ANC e apoiado pelas principais entidades sindicais e partidos políticos de esquerda foi resultado de um trabalho conjunto de todos estes atores mencionados. Contudo, consideramos que o DIAP, ao encabeçar as negociações e assumir uma ação propositora, assumiu um papel de protagonismo na construção do consenso: foi a organização que, por meio de seu corpo técnico-jurídico, elencou as propostas que considerava consensuais para os trabalhadores. Essas propostas foram levadas às mesas de negociação com as diferentes forças envolvidas, momento no qual deve-se ressaltar novamente a importância do prestígio de Ulisses Riedel, bem como sua capacidade articuladora, que legitimou o projeto do DIAP na condição de representativo dos interesses consensuais da classe trabalhadora. Como mostramos, a identificação dos temas considerados consensuais não foi controversa, pois a definição das principais propostas de interesse dos trabalhadores estava respaldada pelo trabalho do DIAP, reconhecido como uma eficiente organização lobista.

Esses fatores somaram-se às características do processo constituinte, as quais favoreceram a participação pública, resultando em uma intensa atuação dos grupos de interesse. 0 Regimento Interno (RIANC) ${ }^{9}$ era profundamente inclusivo do ponto de vista democrático. Destacam-se os procedimentos de democracia direta, a partir das emendas populares e das audiências públicas nas subcomissões da ANC. As duas ferramentas de participação foram amplamente exploradas por grupos de interesse. Outras duas características institucionais incentivaram a participação pública: (1) o fato de a ANC não ter utilizado formalmente nenhum anteprojeto de constituição, ${ }^{10}$ o que, em tese, gerava possibilidades ilimitadas de inserção de direitos e, portanto, criava a percepção entre grupos de interesse da possibilidade de contemplar suas agendas. (2) a estrutura descentralizada da ANC, organizada a partir de comissões e subcomissões temáticas, o que permitiu que os lobbies atuassem diretamente em suas áreas de interesse, facilitando a inserção de suas propostas.

Assim, a Constituinte de 1987-88 abriu uma janela de oportunidades para a participação popular. Ginsburg, Elkins, Blount (2009: 215) defendem a tese de que o público, diante da 
percepção de que as oportunidades são episódicas, busca constitucionalizar direitos que tradicionalmente seriam matéria de legislação ordinária. O processo constituinte brasileiro de 1987-88 é mencionado pelos autores como um exemplo desse fenômeno e classificado como um modelo de participação pública. Essa lógica foi observada no meio sindical, onde era consenso a necessidade de se preparar para a Constituinte. O DIAP foi capaz de organizar os interesses consensuais da classe trabalhadora, criando um projeto, articulado em conjunto com outras organizações sindicais, o qual demonstrou força política durante a Constituinte. De acordo com Queiroz, esse consenso formado durante o processo constituinte não se manteve com a mesma intensidade após 1988. As centrais sindicais CUT e CGT ficaram "enciumadas" com a "atuação ofensiva do DIAP":

[...] pediram para que a gente apenas assessorasse e não criasse fatos, não saísse fazendo grandes encontros. [...] quando a gente se recusou, eles também não fizeram nada. Se há hoje essa desvantagem do movimento sindical, decorre em parte disso. Ele não tinha alguém para segurar a bandeira e defendê-la para manter o movimento vivo. [...] naquele momento, o DIAP representou o conjunto das entidades. Se você verificar aqui vai ver, nós temos a autorização da CUT, da CGT... em documento que o DIAP tem delegação para, em nome dos trabalhadores, atuar no Congresso. Hoje o DIAP atua em nome de seus associados (Queiroz, 1997).

\section{O DIAP NA CONSTITUINTE}

presença de grupos de interesse na Constituinte de 1987-88 foi amplamente divulga-
da pela imprensa, que geralmente os caracterizava de forma negativa. ${ }^{11}$ Os próprios constituintes também manifestaram em diferentes momentos suas suspeitas em relação ao lobby praticado na ANC. O lobby dos trabalhadores, em especial o do DIAP, foi identificado pela imprensa ${ }^{12}$ e por constituintes como um dos mais poderosos e bem organizados. Antes mesmo do início dos trabalhos na Constituinte, o DIAP já era apontado como o "comando" do lobby dos sindicatos de trabalhadores.

Além do apoio das entidades sindicais, o DIAP conseguiu a adesão do PCdoB, PCB, PT e PDT a um documento no qual estes se comprometiam a lutar por seu programa. Alguns partidos, inclusive, credenciaram formalmente representantes para participar das reuniões realizadas pelo DIAP no Congresso Nacional, na sala da Frente Parlamentar Nacionalista. ${ }^{13} \mathrm{Na}$ publicação Quem foi quem na Constituinte (DIAP, 1988), esses representantes são considerados como, na prática, a "força articulada a nível suprapartidário em defesa dos interesses da classe trabalhadora" (DIAP, 1988: 23).

O DIAP atuou na ANC através do acompanhamento dos trabalhos dos parlamentares nas diferentes fases da Constituinte, analisando e divulgando através de boletins (Boletim 
Informativo) e do Jornal do DIAP se estes atuaram em favor ou contra os interesses dos trabalhadores. Esses periódicos eram distribuídos para as entidades sindicais de trabalhadores, membros do Congresso (deputados e senadores), órgãos governamentais e jornalistas da grande imprensa. Assim, o material produzido pelo DIAP era multiplicado a partir da reprodução por diversos grandes jornais e pela imprensa sindical. ${ }^{14}$ Foram atribuídas notas à atuação dos parlamentares, o que resultou na elaboração do Quem foi quem na Constituinte, que foi publicado ao final da Constituinte.

Outra estratégia adotada pela organização foi a elaboração de estudos que eram entregues aos constituintes e aos trabalhadores que compunham sua base eleitoral. 0 uso da informação e a elaboração de estudos foi uma das formas mais importantes de obtenção de legitimidade pela organização, servindo como uma ferramenta de pressão para a aprovação de seus interesses.

Segundo Queiroz, o lobby bem feito consistiu em cooptar figuras "isentas", "de centro", mas simpáticas às propostas do DIAP, o que devia ser feito a partir do uso da informação, através de representantes qualificados que buscassem um apoio pautado na legitimidade das propostas, muito bem articuladas e fruto de extenso e rigoroso trabalho técnico. Ulisses Riedel afirmou em entrevista (Resende, 2011) que as propostas do DIAP eram "científicas" em função do respaldo técnico dos mais influentes advogados trabalhistas da época.

A equipe do DIAP, responsável pelos trabalhos na Constituinte, era composta de 15 membros. ${ }^{15}$ Cabia a essa equipe, primeiro, convocar os técnicos das entidades sindicais alinhadas ao projeto do DIAP. Segundo Queiroz, o DIAP contava com a ajuda de 40 advogados dessas entidades na elaboração de propostas para os trabalhadores. Depois de passar por esse corpo técnico, as propostas eram levadas aos dirigentes sindicais, que davam o respaldo político ao projeto. Além disso, era função dessa equipe manter contato constante com as entidades sindicais dentro da ANC, orientando-as, por exemplo, sobre a forma de abordar o parlamentar: "jamais ser hostil, conhecer e saber defender a proposta que estava apresentando" (Queiroz, 1997). Por fim, havia a pressão direta sobre os parlamentares, que era feita de modo a apresentar as propostas do DIAP junto das justificativas técnicas que as legitimavam. Embora Queiroz negue que fossem feitas chantagens com os constituintes, os membros do DIAP informavam que a decisão do parlamentar seria amplamente divulgada em sua base eleitoral:

[...] a gente estava acompanhando e dizendo desde o primeiro momento: "Olha, o senhor [constituinte] vota como o senhor preferir, tem toda a liberdade, nós estamos apenas the apresentando aqui uma alternativa, mas queremos the informar que vamos divulgar isso amplamente na sua base eleitoral, que sabemos qual é, etc", quer dizer, não é nenhuma chantagem, trabalhamos em grupos de pressão, que se faz o mesmo. (Queiroz, 1997) 
0 DIAP aproveitou eficientemente todas as oportunidades de participação pública na ANC. Destacamos a apresentação de emenda popular e a atuação de Ulisses Riedel em audiência pública na Subcomissão dos Direitos dos Trabalhadores e Servidores Públicos. A emenda popular apresentada pela organização representou a materialização de seu projeto para a Constituinte. Encaminhada em conjunto com a CUT e CGT, ela contou com mais de 272 mil assinaturas (o requisito mínimo para uma emenda popular era de 30 mil). Segundo Barelli (1989), a coordenação do projeto coube ao DIAP, "cuja atuação foi elogiada e temida" (Barelli, 1989 in Michilles et al. 1989: 321.).

Em Costa (2013) é analisada com detalhes a participação de Riedel nas audiências públicas na Subcomissão dos Direitos dos Trabalhadores e Servidores Públicos. Nesse momento o DIAP apresentou, explicou, respondeu a questionamentos e defendeu todas as suas propostas perante a audiência formada de constituintes. Riedel ainda defendeu uma constituição detalhista na área do trabalho, o que condiz com o texto final, mostrando que, assim como os argumentamos, o alto nível de detalhes da Constituição de 1988 é resultado proposital da estratégia de ação de grupos de interesse.

0 texto aprovado na Subcomissão é praticamente idêntico às propostas do DIAP, assim como o anteprojeto elaborado pela Comissão de Ordem Social, no qual a proposta da organização, com algumas alterações pouco significativas, permaneceu intacta. Apenas a partir da fase da Comissão de Sistematização e, sobretudo, durante a fase de votações em plenário o DIAP enfrentou uma resistência mais forte dos empresários, através do Centrão. "Ganhou efervescência o processo constituinte" (DIAP, 1988), referiu-se Antônio Queiroz ao início do primeiro turno de votações em plenário. Foi também durante a fase de plenário que o DIAP começou a usar uma de suas mais importantes e conhecidas ferramentas de pressão, a divulgação das notas dos constituintes. ${ }^{16}$ Com essas notas a imprensa, que já apontava a organização como o mais forte lobby da Constituinte, aumentou seu interesse pela atuação do DIAP e intensificou a divulgação de seu trabalho, publicando uma avalanche de matérias sobre o tema. ${ }^{17}$ Combinado a isso, o conflito entre CUT e CGT colocou o projeto da organização em risco e revelou a complexidade do pacto consensual da classe trabalhadora.

Das propostas defendias pelo DIAP, duas mobilizaram de forma mais radical a oposição do Centrão: a estabilidade no emprego e a jornada de 44 horas semanais. A proposta inicial do DIAP defendia jornada de trabalho de 40 horas, mas esta já havia sido modificada para 44 horas na Comissão de Sistematização. Apesar da pressão do Centrão para alterar a jornada para 48 horas, manteve-se a jornada de 44 horas no texto final da Constituição. A estabilidade, contudo, não foi aprovada, pelo menos não do modo como buscava o DIAP, e como este havia aprovado nas fases anteriores. 
Assim, embora não tenha aprovado todas as suas propostas, o DIAP alcançou importantes conquistas. Segundo Barelli (1989), alguns direitos trabalhistas defendidos pela organização apareceram pela primeira vez em uma constituição brasileira, embora alguns já existissem na legislação da época ou nas negociações trabalhistas. 0 autor lista os seguintes direitos como os mais importantes: 1) garantia contra dispensa imotivada; 2) piso salarial; irredutibilidade de salário; 3) garantia de salário para quem recebe renumeração variável; 4) 13- salário; 5) jornada de seis horas para turnos ininterruptos; 6) remuneração de serviço extraordinário; 7) aviso prévio proporcional; 8) adicional de insalubridade (desdobramento de higiene e segurança); 9) assistência gratuita, até os seis anos, em creches e pré-escolas; 10) proteção em face da automação; 11) prescrição dos créditos resultantes de relações de trabalho; 12) igualdade do avulso com o trabalhador com o vínculo empregatício.

Segundo Barelli (1989), desses direitos, os de número 1, 5, 7, 9, 10 e 11 eram inéditos, não sendo nem mesmo matéria de legislação ordinária. Outros não eram novos, mas foram ampliados, como os conceitos de seguro desemprego, de salário mínimo e de seguro contra acidentes do trabalho. Além disso, foi fixada a jornada de trabalho de 44 horas semanais (eram 48 horas na legislação anterior), a gratificação de férias passou a existir, e ampliou-se a licença de gestante, completada com a licença paternidade.

Assim Riedel avaliou a participação do bloco articulado pelo DIAP na Constituinte:

Geraldo Campos ${ }^{18}$ dizia assim: "Nós saímos com um caminhão de abóbora e perdemos algumas abóboras no meio do caminho. Mas as abóboras que chegaram no fim eram todas nossas". Porque o que está escrito na Constituição eu reconheço, é a minha caligrafia: essa palavra aqui, essa vírgula (Resende, 2011).

\section{CONSIDERAÇÕES FINAIS}

trajetória do DIAP entre 1983 e 1988 revela uma nova história sobre a constituciona-
lização de direitos do trabalho na Carta de 1988. Desde sua origem, o DIAP se concentrou na articulação dos interesses dos trabalhadores, sendo capaz de superar a divisão política entre as principais entidades sindicais da época. A organização articulou um improvável pacto, unindo em um projeto os interesses consensuais das entidades sindicais de trabalhadores, incluindo rivais históricos, como a CUT e a CGT.

A organização também superou as expectativas que sugeriam a elaboração de uma Constituição mais conservadora. A institucionalidade da Constituinte de 1987-88 traz algumas respostas para a compreensão dessa "virada de jogo". Nesse sentido, foi importante a luta para que a Comissão de Sistematização não elaborasse um anteprojeto inicial antes do 
começo dos trabalhos das comissões temáticas. Com isso, ganharam maior importância as subcomissões e comissões, onde os constituintes podiam ser, e foram, mais favoráveis ao projeto do DIAP. Toda a atuação da organização durante essas duas primeiras fases, quando propôs, orientou e pressionou, conseguindo aprovar seu projeto, foi fundamental para que não se perdesse tudo nas fases finais da Constituinte, quando a maioria passou a ser conservadora, portanto, em geral, resistente às propostas do DIAP.

Sustentamos que o sucesso da organização corresponde ao seu desenho institucional, uma adaptação do lobby altamente profissionalizado dos sindicatos de trabalhadores norte-americanos, em especial a AFL-CIO, às oportunidades de participação fornecidas pelo processo constituinte. O DIAP se destacou desde sua criação pela capacidade técnica, a qual pode ser exemplificada pelos diversos estudos e propostas coordenados pela organização e elaborados em pareceria com o corpo jurídico das entidades sindicais a ela filiadas. Esses estudos e propostas eram elaborados com alto rigor técnico, o que lhes dava legitimidade. Além disso, o DIAP mostrou-se eficiente na divulgação de seus interesses, através de publicações periódicas, como o Boletim do DIAP e o Jornal do DIAP, os quais eram distribuídos para as entidades sindicais de trabalhadores, membros do Congresso (deputados e senadores), órgãos governamentais e jornalistas da grande imprensa. Assim, o material produzido pelo DIAP era multiplicado a partir da reprodução por diversos grandes jornais e pela imprensa sindical.

A capacidade de articulação política do DIAP também está associada à sua opção de atuar apenas em defesa de interesses consensuais da classe trabalhadora e à capacidade política de Ulisses Riedel de Resende, seu criador e diretor-técnico. 0 prestígio de Riedel foi fundamental para viabilizar o projeto do DIAP. Influente advogado trabalhista, Riedel era bem relacionado com as principais lideranças sindicais do país, que nele confiavam.

A organização ganhou notoriedade pública antes mesmo do início da Constituinte principalmente através das notas que avaliavam como parlamentares haviam atuado em questões de interesse dos trabalhadores. Nesse sentido, o DIAP publicou em 1986 o livro Quem é quem, que avaliou a atuação dos deputados da legislatura 1983-1986. A divulgação dessas notas se tornou uma de suas mais importantes ferramentas de pressão. Ao final da Constituinte a organização publicou o livro Quem foi quem na Constituinte, que teve uma grande repercussão durante e após a Constituinte.

0 DIAP conseguiu importantes vitórias na Constituinte. A organização acompanhou de perto todas as matérias de interesse para a classe trabalhadora. Na Subcomissão dos Direitos dos Trabalhadores e Servidores Públicos o DIAP apresentou seu projeto em audiências públicas e coordenou os constituintes para que aprovassem suas propostas. 0 relatório final da subcomissão aprovou integralmente o projeto da organização. Verificamos, também, uma 
ampla vitória da organização na Comissão da Ordem Social, na qual, inclusive, foram aprovadas propostas polêmicas do projeto, como a estabilidade no emprego e a jornada de trabalho de 40 horas semanais.

Embora em alguns momentos o consenso das entidades sindicais tenha enfrentado atritos, ele permaneceu sólido durante quase toda a Constituinte. No momento em que mais sofreu pressões, reflexo, sobretudo, da rivalidade entre a CUT e a CGT, a ANC já estava próxima de seu fim. A atuação do DIAP encontrou mais resistência quanto maior era o número de constituintes necessários para aprovar suas propostas.

Consideramos o saldo final amplamente favorável aos interesses dos trabalhadores, sobretudo se lembrarmos as expectativas negativas nos anos que antecederam à Constituinte. As duas maiores derrotas do DIAP foram a não aprovação da estabilidade no emprego e da jornada de 40 horas, a qual foi alterada para 44 horas no texto do anteprojeto da Comissão de Sistematização. Apesar desses reveses pontuais, a Constituição de 1988 ficou marcada na história pelo amplo espaço concedido aos direitos sociais e do trabalho.

A atuação dos partidos políticos de esquerda e, principalmente, da parcela progressista do PMDB foi fundamental, mas insuficiente para entender a ampliação de direitos da Constituição brasileira. Acreditamos que a constitucionalização de direitos sociais e do trabalho constitui uma tendência internacional, claramente observada nas reformas mais recentes, em especial na América do Sul. Esse fenômeno é resultado de processos constituintes marcados por alto nível de participação popular. Sustentamos que a intensa participação de grupos de interesse influenciou diretamente na elaboração de constituições detalhadas e programáticas. No caso brasileiro, mostramos evidências que suportam a influência de grupos de interesse, articulados pelo DIAP, na constitucionalização de interesses dos trabalhadores.

\section{Notas}

1 As constituições da Venezuela de 1999, do Equador de 2008 e da Bolívia de 2009 estão entre as mais detalhadas do mundo no que diz respeito à presença de direitos sociais e do trabalho. Alguns autores, como Nolte e Schilling-Vacaflor (2012), consideram os processos de reforma constitucional nesses países como um "novo constitucionalismo" devido às suas características peculiares, entre as quais a ampla participação pública, com a presença de diversos mecanismos de democracia direta.

2 Há uma ampla discussão na literatura sobre o conceito de lobbye as particularidades do lobbyno Brasil (Mancuso, 2004; Mancuso e Gozetto, 2011; Costa, 2014). Conforme Pasquino (1998), definimos lobby como um processo por meio do qual representantes de grupos de interesse, agindo como intermediários, levam aos legisladores ou aos decison-makers os desejos de seus grupos. Esta transmissão de mensagens pode ser feita de diversas formas, compondo as diferentes estratégias de lobby. Neste artigo discutimos as estratégias usadas pelo DIAP.

3 A AFL-CIO congrega 13 milhões de trabalhadores. É a maior central sindical norte-americana. Informações obtidas através do site oficial da entidade: www.aflcio.org. 
4 Trata-se do Decreto no 88.888, de 19 de outubro de 1983, o qual determinou a adoção de "Medidas de Emergência", com o objetivo de "preservar a ordem pública em áreas localizadas no Distrito Federal ameaçadas de grave perturbação" (BRASIL, 1983). Entre as medidas estabelecidas pelo decreto, incluíam-se "busca e apreensão em domicilio; suspensão da liberdade de reunião e associação; intervenção em entidades de classes ou categorias profissionais (...)" (Estado de S. Paulo, 20/10/1983). Ao restringir a manifestação pública no Distrito Federal, o governo pretendia limitar a pressão popular sobre a votação do Decreto-Lei 2.045, 0 qual pretendia aprovar. 0 decreto tratava da política salarial e era tido como prejudicial à classe trabalhadora (Vesentini, 1986).

5 A questão da organização sindical era um dos principais pontos que dividiam politicamente as entidades sindicais de trabalhadores nos anos 1980. 0 principal debate se dava em torno da Convenção no 87, de 1948, da Organização Internacional do Trabalho, que tratava de temas como liberdade sindical e direito de sindicalização. Dentro do cenário sindical brasileiro esses pontos tocavam interesses ligados à própria sobrevivências das entidades sindicais. Alguns líderes sindicais, como Antônio Pereira, representante da União Sindical Independente (USI), eram contra os dispositivos aprovados pela convenção, por entenderem que a liberdade sindical transferiria, na prática, o poder de decisão sobre a sindicalização ao empregador, colocando em risco a existência das entidades sindicais. Conforme Riedel ressaltou durante depoimento na ANC, o DIAP optou por oficialmente não tomar partido diante da questão, uma vez que não se tratava de tema consensual no meio sindical: "a matéria é extremamente complexa, extremamente delicada. E o DIAP não tem e não pode ter posição dele, porque não existe como órgão, ele não é central sindical, ele não tem posturas próprias. A sua postura é de tentar encontrar um equilíbrio que seja possível atender às posições de um agrupamento e de outro" (Brasil, 1987a: 63).

6 A proposta do DIAP para o salário mínimo se baseava em dois pontos centrais: (1) impedir que o salário mínimo fosse fixado por meio de decretos do Executivo, ou seja, garantir apenas ao Congresso Nacional a prerrogativa de estabelecer os valores dos salários mínimos; (2) acrescentar outros elementos que o salário mínimo deveria cobrir. Aos já previstos (alimentação, moradia, vestuário, higiene e transporte) deveriam ser adicionados: educação, lazer, saúde e Previdências Social, pois, conforme Riedel, "a não inclusão desses itens importaria em dizermos que o trabalhador não precisa de nenhuma verba para a educação, que não precisa de nenhum centavo para o lazer, que não precisa de nenhuma importância para a saúde e que é admissível que seja descontado do mínimo o valor da Previdência Social. Se é o mínimo, não é possível que haja um desconto ainda de Previdência Social" (Brasil, 1987a: 60).

70 Art. 3o do Atos das Disposições Constitucionais Transitórias da Constituição de 1988 estabelecia a realização do processo de revisão constitucional decorridos cinco anos de sua promulgação. 0 processo de revisão, que se iniciou em 7 de outubro de 1993, teve duração de 237 dias, período no qual os membros do Congresso Nacional reunidos em sessões unicamerais apresentaram projetos de emenda constitucional, os quais poderiam ser aprovados com maioria simples.

8 "Lobista: aquele que aparece na hora certa com o dado certo", Jornal da Tarde (25.06.1987).

90 Regimento Interno da Assembleia Nacional Constituinte (RIANC) definiu as regras do jogo dentro da ANC e foi motivo de impasses entre os constituintes em diferentes momentos, chegando a ser alterado em fase decisiva da Constituinte devido à manobra do Centrão, grupo suprapatidário de centro-direita formado com o objetivo principal de frear os elementos mais progressistas que vinham consagrando o texto constitucional.

10 Em julho de 1985 foi instituída a Comissão Provisória de Estudos Constitucionais, que ficou mais conhecida como "Comissão Afonso Arinos", por ter sido presidida pelo consagrado jurista Afonso Arinos de Melo 
Franco. Dessa comissão resultou um anteprojeto constitucional que foi entregue ao presidente Sarney. Esse anteprojeto, no entanto, não foi oficialmente usado como base dos trabalhos constitucionais. Segundo Pilatti (2008), a Comissão Arinos foi criticada pela esquerda e por entidades civis e religiosas que desempenharam papel importante na resistência ao regime militar a partir dos anos 1970.

11 Há centenas de referências em notícias e artigos de opinião sobre o lobby e os grupos de interesse na ANC. Ver, por exemplo, matéria do Jornal de Brasília (06.11.1987) intitulada "Plenário é alvo de pressões".

12 Essa força do lobby do DIAP era apontada já no início dos trabalhos na ANC, revelando a importância do preparo que a organização teve nos anos anteriores ao início da Constituinte. Ver, por exemplo: Folha de S. Paulo (1.02.1987) e (21.06.1987); Jornal de Brasilia (06.11.1987); Gazeta Mercantil (03.02.1987), (22.06.1988) e (08.11.1988); Jornal da Tarde (25.06.1987); Estado de S. Paulo (24.06.1987); Correio Braziliense (30.11.1987).

13 A lista destes nomes, assim como uma análise da influência que exerceram, é encontrada em Costa (2013).

14 Levantamento feito pela Escola de Comunicações e Artes da Universidade de São Paulo (ECA-USP) mostrou que as entidades sindicais e intersindicais foram responsáveis, durante a Constituinte, pela publicação de 12 milhões de panfletos, boletins e jornais impressos todo mês, número que equivalia a 10\% da tiragem total declarada dos jornais brasileiros em um mês. O Jornal do DIAP, impresso mensalmente pela organização, tinha, na época, uma tiragem mensal de 10 mil exemplares que eram distribuídos gratuitamente, conforme mostrado acima.

15 No final de 1997, quando foi realizada a entrevista, o DIAP contava com uma equipe de 12 membros, uma redução em relação ao período da Constituinte.

16 Para mais detalhes sobre o impacto da estratégia de atribuir notas aos constituintes, ver Costa (2013: 96-100).

17 Para o DIAP, em Quem foi quem na Constituinte, essa era uma estratégia para convocar a reação para enfrentar os avanços do projeto da classe trabalhadora: "O DIAP foi elogiado em editoriais da grande imprensa por seu trabalho. Na verdade, é óbvio, não queriam elogiar o nosso trabalho, mas apenas convocar a reação aos avanços obtidos no Projeto de Constituição" (DIAP, 1988: 24).

180 então senador Geraldo Campos (PMDB/DF) foi o presidente da Subcomissão dos Direitos dos Trabalhadores e Servidores Públicos na ANC.

\section{REFERÊNCIAS BIBLIOGRÁFICAS}

ARAGÃO, Murillo de. Grupos de pressão no Congresso Nacional. São Paulo: Maltese, 1994.

BARELLI, Walter. Os direitos dos trabalhadores. In: MICHILES, Carlos et al. Cidadão constituinte: a saga das emendas populares. Rio de Janeiro: Paz e Terra, 1989.

BLOUNT, Justin. Participation in constitutional design. In: Comparative Constitutional Law. Edited by Tom Ginsburg and Rosalind Dixon, 2011.

BRASIL. ASSEMBLEIA NACIONAL CONSTITUINTE. Atas da Subcomissão dos Direitos dos Trabalhadores e Servidores Públicos. Brasília: Centro Gráfico do Senado Federal, 1987a.

. Atas da Comissão da Ordem Social. Centro Gráfico do Senado Federal, 1987b. 
Decreto no 88.888, de 19 de outubro de 1983. Dispõe sobre o estabelecimento de Medidas de Emergência na área do Distrito Federal e dá outras providências.

COELHO, R. Partidos políticos, maiorias parlamentares e tomada de decisão na Constituinte. Doutorado (Ciência Política), USP. São Paulo: 1999.

COMIN, A. A experiência de organização das centrais sindicais no Brasil. In: 0 mundo do trabalho - Crise e mudança no final do século. São Paulo: Página Aberta, 1994.

A estrutura sindical corporativista: limite ao fortalecimento das centrais sindicais. Sociologia, USP, São Paulo, 1995.

COSTA, Lucas N. F. As organizações sindicais de trabalhadores e o processo constituinte de 1987-88: um estudo sobre a atuação do DIAP. Dissertação (Mestrado em Ciência Política) -PPG-Pol - UFSCar), 2013.

The lobby in the Brazilian constituent process of 1987-88. 23rd World Congress of Political Science. Montreal, Canada, 19-24 jul. 2014.

Modelos de lobby no processo constituinte de 1987-88. Agenda Política, v.3, p. 70-97, 2015.

e TROIANO, Mariele. DIAP versus Fiesp: uma análise de organizações representativas em um período de mudança institucional. In: Anais do IV Seminário Nacional de Ciência Política - Teoria e Metodologia em Debate, Porto Alegre, 2011.

DIAP. Quem foi quem na constituinte: nas questões de interesse dos trabalhadores. São Paulo: Editora Cortez, 1988.

ELKINS, Zachary, GINSBURG, Tom, MELTON, James. The Endurance of National Constitutions. Leiden: Cambridge University Press, 2009.

GINSBURG, Tom, ELKINS, Zachary, BLOUNT, Justin. Does the Process of Constitution-making Matter, Annual Review of Law and Social Science 5, 2009, p. 201-223.

MANCUSO, P. W. O lobby da indústria no Congresso Nacional: empresariado e política no Brasil contemporâneo. Dados - Revista de Ciências Sociais, vol. 47, n. 3. Rio de Janeiro, 2004.

\& GOZETTO, A. C. O. Lobbying: instrumento democrático de representação de interesses? Organicom (USP), v. 8, p. 118-128, 2011.

MICHILES, C. et al. Cidadão constituinte: a saga das emendas populares. Rio de Janeiro: Paz e Terra, 1989.

NOLTE, Detlef; SCHILING-VACAFLOR, Almut. New Constitutionalism in Latin America. Ashgate, 2012.

NORONHA, E. G. Greves na transição brasileira. Dissertação (Mestrado), Universidade Federal de Campinas - Unicamp, 1992.

Greves e estratégias sindicais no Brasil. In: OLIVEIRA, C. A. D.; MATOSO, J. E. L. et al. (eds.). O mundo do trabalho. Crise e mudança no final do século. São Paulo: Ministério do Trabalho; Centro de Estudos Sindicais e de Economia do Trabalho - CESIT; Scritta. 1994.

Entre a lei e a arbitrariedade - mercados e relações de trabalho no Brasil. São Paulo: LTr, 1999.

Ciclo de greves, transição política e estabilização: Brasil, 1978-2007. Lua Nova, n.58, p.119-168, 2009.

NORONHA, Eduardo G.; COSTA, Lucas N. F.; TROIANO, Mariele. Direitos sociais e do trabalho: um estudo comparado das constituições de 1934 a 1988. Anais Eletrônicos do IX Encontro da Associação Brasileira de Ciência Política, 2014. 
OLIVEIRA, A. C. J. 0 lobbying do trabalhador no Congresso Nacional. Revista Medições. Londrina, v. 10, n. 2 , p. 219-236, 2005.

PASQUINO, Gianfranco. Grupos de pressão. In: BOBBIO, N., MATTEUCCI, N. e PASQUINO, G. (org.). Dicionário de política. Brasília: Editora Universidade de Brasília, 1998.

PILATTI, A. A Constituinte de 1987-1988: progressistas, conservadores, ordem econômica e regras do jogo. Rio de Janeiro: Lumen Juris, 2008.

QUEIROZ, Antônio Augusto de. O DIAP na Constituinte 1987-88. Brasília, 21 nov. 1997.

RESENDE, Ulisses Riedel de. DIAP e o "Quem foi quem na Constituinte". Brasília, União Planetária, 8 abr. 2011.

RODRIGUES, José Albertino. Sindicato e desenvolvimento no Brasil. São Paulo: Símbolo, 1979.

RODRIGUES, Lêoncio Martins. O futuro do sindicalismo no Brasil. São Paulo: Pioneira, 1990.

. As tendências políticas na formação das centrais sindicais. In: BOITO JR., A. (Ed.). O sindicalismo brasileiro nos anos 80. São Paulo: Paz e Terra, 1991, p.12-46.

SAMUELS K., WYETH, V.H. State-Building and Constitutional Design After Conflict. New York: Int. Peace Acad. 2006.

SANTOS, M. A. Associação Comercial da Bahia na Primeira República. Um grupo de pressão. Associação Comercial da Bahia, Salvador, 1991 (2a ed.).

SILVA, Antônio Álvares da. Marcos legais do corporativismo no Brasil. In: O mundo do trabalho - crise e mudança no final do século. São Paulo: Editora Página Aberta, 1994.

TROIANO, M. As associações empresariais e o processo constituinte de 1987-88. Dissertação (Mestrado em Ciência Política) - PPG-Pol - UFSCar, 2012.

VESENTINI, J. W. A capital da geopolítica. Editora Ática, 1987.

\section{JORNAIS IMPRESSOS E ONLINE}

AFL-CIO. <www.aflcio.org>

Correio Braziliense (30.11.1987).

DIAP. Agência DIAP - Dom, 7 de dezembro de 2008.

Gazeta Mercantil (03.02.1987), (22.06.1988), (08.11.1988).

Estado de S. Paulo (20.10.1983), (24.06.1987).

Folha de S. Paulo (1-02-1987), (21.06.1987).

Jornal da Tarde (25.06.1987).

Jornal de Brasília (06.11.1987) 